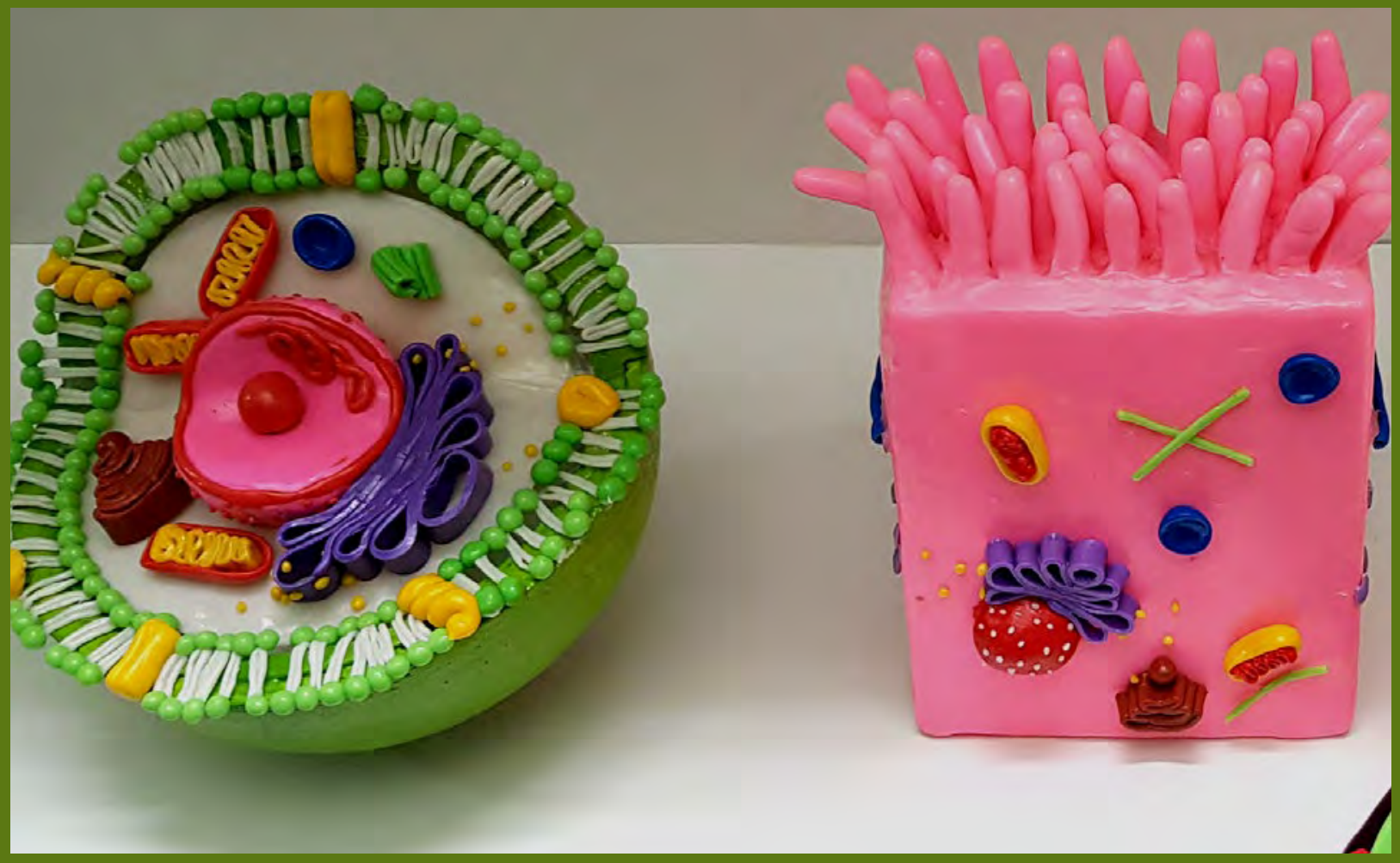

\title{
Utilização de modelos celulares em biscuit como prática alternativa para o ensino de Biologia
}

Igor Cunha Trindade - igorcunha.uftm@gmail.com ${ }^{1}$

Carla Fernanda de Paula Chimenes - carlanandastz@hotmail.com ${ }^{2}$

Hilara Niemeyer Ruas - hilaraniemeyer@hotmail.com ${ }^{3}$

Marcos de Lucca Moreira Gomes - marcos.gomes@uftm.edu.br ${ }^{4}$

\section{RESUMO}

Buscando a integralização no processo educativo, este relato de experiência procurou demonstrar que a utilização de modelos celulares em biscuit auxilia e enriquece a compreensão do conhecimento em Biologia Celular, além de facilitar a articulação entre teoria e prática impactando vigorosamente no processo de formação docente.

PALAVRAS-CHAVE: modelos celulares; processo educativo; biscuit; formação discente.

1 Discente do curso de graduação em Ciências Biológicas (UFTM)

2 Discente do curso de graduação em Biomedicina (UFTM).

3 Discente do Curso de Pós-Graduação em Ciências da Saúde (UFTM).

4 Doutor em Biologia Celular e Estrutural, Professor da UFTM. 


\title{
Use of cellular models in biscuit as an alternative practice for teaching Biology
}

\begin{abstract}
Seeking to integrate in the educational process, this experience report sought to demonstrate that the use of cellular models in biscuit helps and enriches the understanding of knowledge on Cell Biology, and also favors the articulation between theory and practice, vigorously influencing the student formation process.
\end{abstract}

KEYWORDS: cell models; educational process; biscuit. student formation.

\section{RELATO DE EXPERIÊNCIA}

Diante da importante função da extensão universitária, vista como um processo na busca da promoção do conhecimento acadêmico a toda a sociedade, o trabalho apresentado neste relato de experiência explorou a aplicação de metodologias ativas como possibilidade da aprendizagem dinâmica e contínua, com o uso de modelos didáticos confeccionados em biscuit ${ }^{5}$, de modo a facilitar a compreensão de conhecimentos de Biologia nas escolas. Com o intuito de reafirmar o papel das Universidades na formação de cidadãos compromissados e conscientes com os anseios sociais, conciliando o conhecimento acadêmico às necessidades educacionais da comunidade no município, procurou-se utilizar práticas pedagógicas relacionadas à socialização e às atividades em grupo, discorrendo acerca da conscientização no uso de materiais alternativos na prática pedagógica, diversificando o processo de ensino com o intuito de criar oportunidades aos alunos com dificuldades de aprendizagem.

Giordan e Vecchi (1996) descrevem os modelos como "elementos facilitadores que os educadores podem utilizar para ajudar a vencer os obstáculos que se apresentam no difícil caminho da conceitualização". Modelos e jogos didáticos são alternativas que podem ser abordadas e favorecem o processo de ensinoaprendizagem (BEVITÓRIO et al., 2019). Em especial no ensino da Biologia, essa interação dos modelos construídos no presente projeto teve o intuito de servir como instrumento auxiliar para a prática pedagógica, por serem mais atraentes e motivadores que as tradicionais aulas expositivas praticadas na maioria dos centros educacionais para a construção do conhecimento. Além de retratar com mais realidade assuntos abordados em aulas convencionais, os modelos aproximam aspectos figurativos das estruturas tornando-as mais descomplicadas, pois materializam um conceito teórico.

Nossa proposta de interação e facilitação no ensino de Biologia foi apresentada aos alunos do nono ano do Ensino Fundamental II da Escola Estadual Marechal Humberto de Alencar Castelo Branco (EEMHACB) e do Colégio Tiradentes da Polícia Militar de Minas Gerais, ambos localizados no município de Uberaba/MG. A atividade é resultado do Projeto de Extensão desenvolvido na Universidade Federal do Triângulo Mineiro (UFTM) com alunos de graduação em Biomedicina e Ciências Biológicas. Foram realizadas atividades de março a julho de 2019, sendo duas visitas para realização de reuniões com os docentes do componente curricular Biologia e cinco visitas para realização das práticas.

As atividades foram realizadas em três momentos: planejamento do material junto aos docentes nas escolas e integração com a comunidade escolar, apresentação das estruturas aos alunos, e curso para confecção de modelos didáticos no câmpus da UFTM.

No planejamento, optou-se por confeccionar modelos retirados da bibliografia recomendada e já estudada no conteúdo programático normal do nono ano em ambas as escolas, mantendo-se o cronograma normal de atividades já determinado pelos professores de Biologia. Assim, as atividades com biscuit foram feitas durante suas aulas regulares. Como relatado também por Perini e Rossini (2018), procurou-se utilizar materiais de fácil aquisição e baixo custo: massa pronta de biscuit, tintas de tecido, cola, arame, isopor, papel camurça e pinceis. Um dos objetivos foi confeccionar materiais capazes de proporcionar visuais

5 Massa de modelar produzida a partir da mistura de amido de milho, cola branca para porcelana fria, conservantes como limão ou vinagre e vaselina. 
coloridos e atraentes, proporcionando o estímulo por meio da manipulação das peças pelos estudantes (Figura 1). Ademais, foram adicionadas legendas em braile ao material, estimulando a discussão da inclusão de ferramentas extras para alunos que porventura apresentem quaisquer graus de deficiência visual. As oficinas de montagem contaram com a presença obrigatória dos monitores e docentes responsáveis, que orientaram todo o processo junto aos alunos.

Figura 1 - Modelos celulares didáticos confeccionados em massa de biscuit.

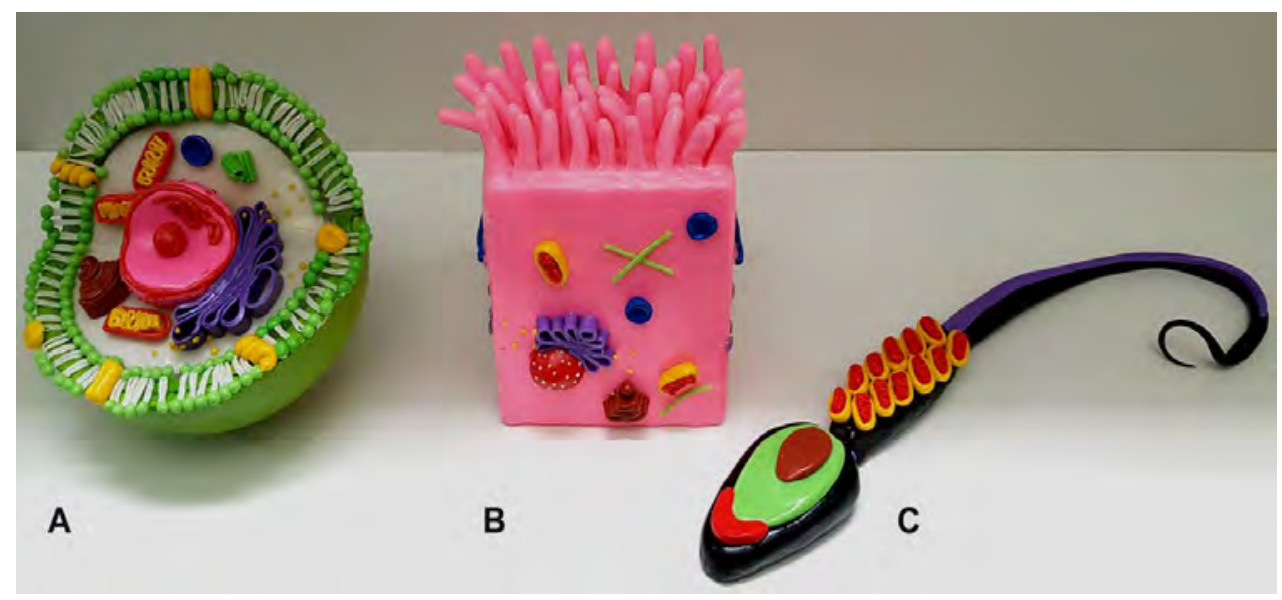

A. Célula eucariota. B. Enterócito. C. Espermatozoide.

FONTE: Arquivo pessoal (dados da pesquisa).

Utilizando-se os modelos confeccionados, foram realizadas aulas práticas como atividade complementar à teoria e estas foram apresentadas aos alunos nas escolas (Figura 2). Ao final do projeto, foi oferecido curso mais detalhado em laboratório prático da UFTM para confecção de peças em biscuit para os discentes interessados. Todas as peças produzidas nas oficinas foram doadas às respectivas escolas, para exposição em sala de aula.

Figura 2 - Alunos interagindo e discutindo os modelos didáticos

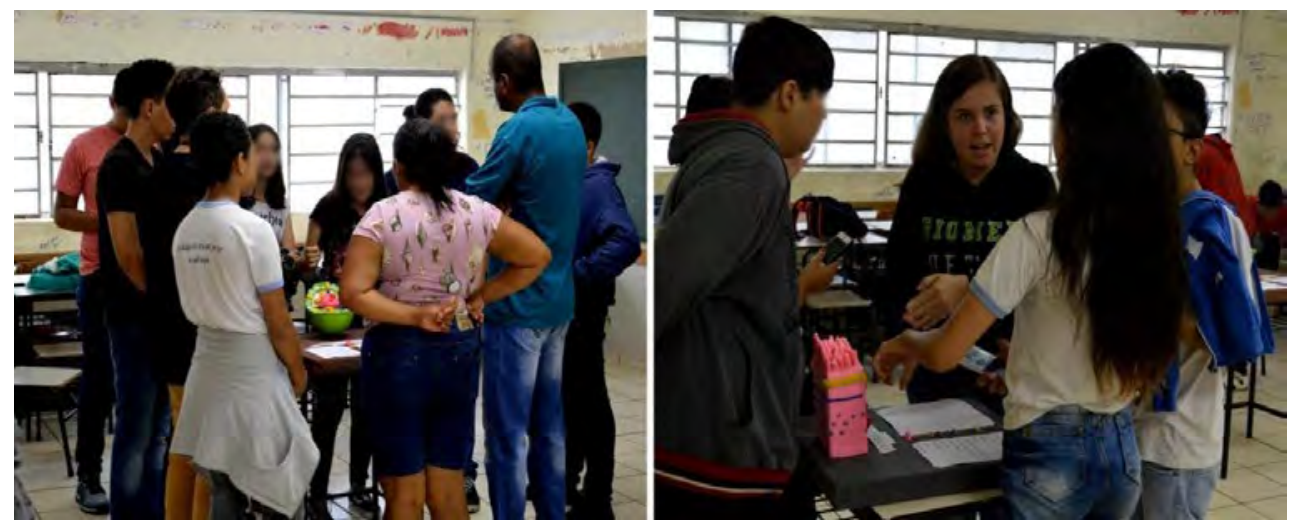

FONTE: Dados desta pesquisa.

Como parte do processo avaliativo, foram elaborados opinários com questões que procuravam entender a percepção dos discentes e docentes com relação às práticas propostas (Fig. 3). Tais perguntas foram feitas em ambas as escolas parceiras e mostraram resultados positivos, comprovando a eficácia da metodologia utilizando-se modelos em biscuit, ou seja, este método permitiu uma aprendizagem significativa por parte dos alunos, sendo estes agentes mais ativos no processo. Souza et al. (2016) indicam que o interesse aumenta em aulas práticas, pois os alunos tornam-se motivados, uma vez que os modelos trazem elementos do seu cotidiano, são coloridos, têm cheiro e significado, tornando a aula interessante. Assim, os alunos se interessam pelo conteúdo abordado, fazem perguntas, demonstram opiniões e geram discussões, 
sendo estes aspectos importantes no aprendizado. Além deles, os próprios professores mostraram-se interessados e empolgados com a proposta, indicando que podem utilizar esta metodologia em aulas práticas futuras, acreditando que atividades lúdicas podem estimular e facilitar o trabalho com o conteúdo teórico, sem demandar grande infraestrutura e remanejamento de aulas para tal.

Em relação à adesão dos alunos, podemos afirmar que o trabalho teve uma aprovação significativa, pois:

[...] as novas ferramentas como a confecção de modelos didáticos com massa de biscuit desenvolvem uma interação melhor entre os alunos em sala de aula, uma vez que, o esforço para modelar as estruturas de maneira fiel e representativa levaos a uma aprendizagem continuada, consistindo em uma estratégia alternativa, no que se refere ao Ensino Fundamental (SOUZA E ALVES, 2016, p. 12).

As principais dificuldades observadas no decorrer do projeto deram-se pela indisciplina dos alunos quando apresentados a uma metodologia nova. Uma vez que algo novo pode trazer certa insegurança, evidenciou-se uma pequena hesitação quando expostos ao trabalho de modelar as peças no curso. Entretanto, com o decorrer do evento, eles foram se familiarizando com o método. A aceitação do curso foi tamanha que os alunos confeccionaram duas peças após o término das explicações teóricas sobre o manuseio do biscuit. A primeira peça foi um órgão, o coração, seguido de uma peça do ácido desoxirribonucleico (DNA). As técnicas utilizadas na confecção durante o decorrer do curso prático poderão ser aplicadas nas respectivas escolas, fazendo com que o estudo de conteúdos mais complexos seja facilitado.

Este projeto demonstrou que as relações entre atividades de ensino e de extensão universitária apresentam um resultado positivo na interação universidade-sociedade. Além disso, através dessa abordagem interativa com os estudantes, percebeu-se que as metodologias ativas enriquecem o aprendizado e facilitam a articulação entre teoria e prática. Neste trabalho, notamos que os modelos didáticos são formas alternativas, viáveis e divertidas de se trabalhar os conteúdos de Biologia. Sugerimos aos docentes a aplicação de tais estratégias para tornar as aulas mais atrativas e dinâmicas, estimulando o estudante a participar e ser sujeito da sua aprendizagem.

\section{Figura 4 - Opinários como método avaliativo aplicado após a execução do projeto}
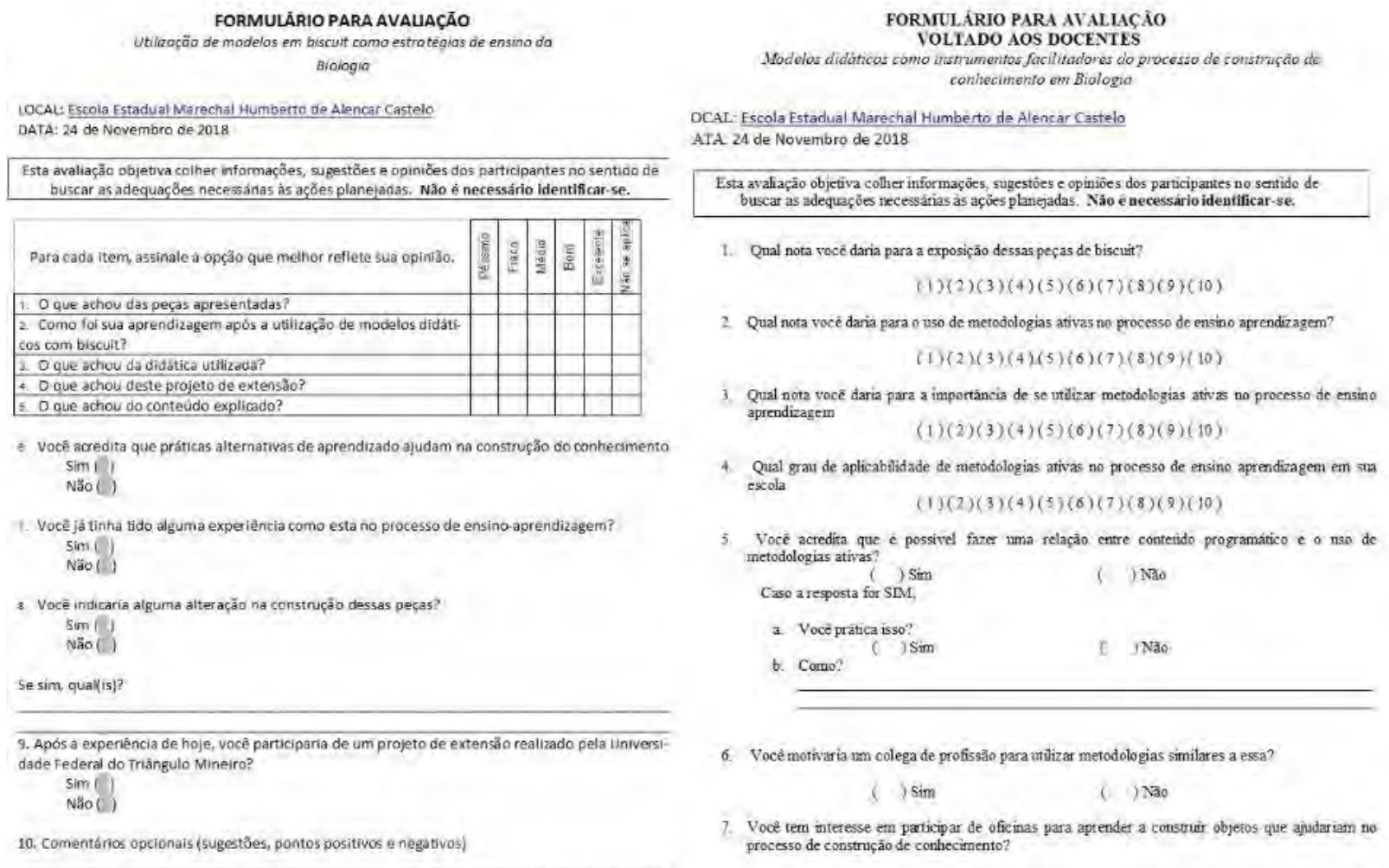

FONTE: Dados da pesquisa. 
0 trabalho junto a discentes e docentes no ambiente escolar nos fez perceber as reais necessidades do público-alvo e buscar estratégias facilitadoras para construção do conhecimento. Portanto confirmamos que a atividade de extensão é uma parte indispensável e integrante na formação, pois interliga a Universidade às demandas da comunidade, de forma a compreender e reverberar em suas práticas o seu caráter humano, social e científico.

\section{REFERÊNCIAS}

BEVITÓRIO, Lorena Ziviani; GOMES, Marcos Lucca Moreira; MONTEIRO-PIROVANI, Juliana Castro. Uso de jogos didáticos como estratégia para o ensino de educação sexual no ensino médio. Enciclopédia Biosfera. v. 16, n.30, p. 614-629. 2019.

GIORDAN, André; VECCHI, Gérard. As origens do saber. 2. ed. Porto Alegre: Artes Médicas, 1996.

PERINI, Monique; ROSSINI, Josiene. Aplicação de modelos didáticos no ensino de biologia floral. International Scientific Journal. v.13, n.3, p.58-71, 2018.

SOUZA, Mayara Medaglia Leães; SOUZA, Paulo Sérgio; RAMOS, Maurivan Güntzel. 0 interesse dos alunos em aprender ciências e matemática na escola. CCNEXT - Revista de extensão, v. 3, p.1015-1021, 2016.

SOUZA, Ruanna Thaimires Brandão; ALVES, Maria Helena. Modelos didáticos com massa de biscuit: inovando no ensino de ciências e biologia. Revista Espacios, v.37, n. 29, p.8-17, 2016. 